\title{
ТЕРРИТОРИАЛЬНОЕ ЭКОЛОГИЧЕСКОЕ РАВНОВЕСИЕ МУНИЦИПАЛИТЕТОВ РЕСПУБЛИКИ КОМИ
}

\author{
Мазуркин П. М., Куклина А. П.
}

(Поволжский государственный технологический университет, г. Йошкар-Ола)

До проектирования экологически ответственных, социально приемлемых и экономически эффективных мероприятий по природоохранному обустройству территорий, защите окружающей человека природной среды и рационализации промышленного природопользования (прежде всего в процессах землеустройства и землепользования, водопользования и лесопользования) необходимо провести предпроектные изыскания земельных участков с растительным покровом и исследования их параметров функционирования.

При этом изучение череды состояний во времени даёт динамику поведения природных и культурных ландшафтов, а также позволяет дискретно оценивать устойчивость, экологический ущерб и риски от антропогенных и иных воздействий на эти изменяющиеся во времени и пространстве ландшафты.

Главной подсистемой ландшафта является растительный покров, который за столетия и десятилетия формирует почвенный покров [1-3].

Вначале рассматривается территориальный экологический баланс, так как для компонентного анализа необходимы данные измерений видового разнообразия растительности, её сукцессии и мозаичности по однородным земельным участкам (леса, луга, болота и др.).

Цель - повышение рекреационной привлекательности на основе анализа показателей экологического равновесия по муниципалитетам и выявления закономерностей распределения земельных участков и муниципалитетов.

Для достижения этой цели необходимо решить следующие задачи: 1) провести анализ научно-технической литературы; 2) собрать данные по земельным фондам муниципальных образований республики Коми за 2010 год; 3) рассчитать количественные критерии активности растительного покрова по муниципалитетам и их группам; 4) обработать данные в программной среде Curve Expert - 1.3; 5) получить устойчивые биотехнические закономерности распределения площадей территорий; 6) разработать рекомендации по целесообразному управлению земельными ресурсами.

Впервые было рассмотрено территориальное экологическое равновесие, а также закономерности распределения земельных участков по муниципалитетам Республики Коми.

Республика Коми обладает большими земельными, биологическими, водными, а также уникальными по разнообразию и качеству минерально-сырьевыми ресурсами (валовая ценность запасов полезных ископаемых республики достигает 11 трлн. долларов США или 8\% прогнозного потенциала России), которые являются основой развития производительных сил. В связи с этим ведущее положение в народном хозяйстве республики занимают добывающие отрасли промышленности, где главную роль играет топливно-энергетический комплекс (до 97\%), в его составе выделяются угольная, нефтяная и газовая промышленность. Вторым по значению в экономике республики является лесопромышленный комплекс (общая площадь лесов Республики Коми составляет 38,9 млн. га или 3,5\% всех лесов России и около 50\% площади лесов Европейского Севера России). 
Рекреационный потенциал Республики Коми привлекателен в силу экологической чистоты природной среды, хорошей сохранности таёжных и речных экосистем, экзотичности горных ландшафтов. Очевидно, что в число самых ценных входит имеющаяся в настоящее время в Республике Коми достаточно развитая сеть особо охраняемых природных территорий. В республике функционируют 239 ООПТ, две из которых имеют федеральное значение и 237 - региональное. Общая площадь природных резерватов более 6 млн. га, что составляет 14,5\% от площади республики.

В соответствии с данными государственного учёта земель общая площадь земельного фонда Республики Коми по состоянию на 01.01.2011 г. осталась без изменений и составила 41677,4 тыс. га. Распределение земельного фонда по категориям земель и по угодьям приведено в таблице 1.

Таблица 1

Распределение земельного фонда по категориям земель Республики Коми

\begin{tabular}{|c|c|c|c|c|c|c|c|c|c|c|c|}
\hline \multirow{3}{*}{ Категория земель } & \multicolumn{11}{|c|}{ Площадь } \\
\hline & \multicolumn{2}{|c|}{$\begin{array}{c}\text { на } \\
01.01 .07\end{array}$} & \multicolumn{2}{|c|}{$\begin{array}{c}\text { на } \\
01.01 .08\end{array}$} & \multicolumn{2}{|c|}{$\begin{array}{c}\text { на } \\
01.01 .09\end{array}$} & \multicolumn{2}{|c|}{$\begin{array}{c}\text { на } \\
01.01 .10\end{array}$} & \multicolumn{2}{|c|}{$\begin{array}{c}\text { на } \\
01.01 .11\end{array}$} & \multirow{2}{*}{$\begin{array}{c}\text { изменение, } \\
\text { тыс. га }\end{array}$} \\
\hline & тыс. га & $\%$ & тыс. га & $\%$ & тыс. га & $\%$ & тыс. га & $\%$ & тыс. га & $\%$ & \\
\hline 1 & 1855,8 & 4,5 & 1856,0 & 4,5 & 1856,2 & 4,5 & 1855,1 & 4,5 & 1862,9 & 4,5 & $+7,8$ \\
\hline 2 & 197,3 & 0,5 & 197,3 & 0,5 & 197,3 & 0,5 & 198 & 0,5 & 198,3 & 0,5 & $+0,3$ \\
\hline 3 & 271,1 & 0,7 & 270,3 & 0,6 & 270,1 & 0,6 & 263,0 & 0,6 & 270,3 & 0,6 & $+7,3$ \\
\hline $4^{*}$ & 2613,1 & 6,3 & 2613,1 & 6,3 & 2613,2 & 6,3 & 2613,2 & 6,3 & 2613,2 & 6,3 & 0 \\
\hline $5^{* *}$ & 35950,1 & 86,3 & 35950,7 & 86,3 & 35950,8 & 86,3 & 35958,6 & 86,3 & 35958,6 & 86,3 & - \\
\hline 6 & 142,5 & 0,3 & 142,3 & 0,3 & 142,3 & 0,3 & 142,2 & 0,3 & 142,0 & 0,3 & $-0,2$ \\
\hline 7 & 647,5 & 1,6 & 647,7 & 1,6 & 647,5 & 1,6 & 647,3 & 1,6 & 632,1 & 1,5 & $-15,2$ \\
\hline Итого земель & 41677,4 & 100,0 & 41677,4 & 100,0 & 41677,4 & 100,0 & 41677,4 & 100,0 & 41677,4 & 100 & 0 \\
\hline
\end{tabular}

Примечание. Здесь и далее обозначены категории земель: 1 - земли сельскохозяйственного назначения; 2 - земли населённых пунктов; 3 - земли промышленности, энергетики, транспорта, связи, радиовещания, телевидения, информатики, земли для обеспечения космической деятельности, земли обороны, безопасности и земли иного специального назначения; 4 - земли особо охраняемых территорий и объектов; 5 - земли лесного фонда; 6 - земли водного фонда; 7 - земли запаса.

Земли по муниципалитетам. Дана краткая характеристика 20 муниципальных образований. Приведены фактические данные по их земельным фондам за 2010 год. Проведён анализ качественного состояния земель. Каждое муниципальное образование Республики Коми в отдельности отличается по данным земельного кадастра по состоянию на 01.01.2011. Подробно рассмотрим на примере МО ГО «Сыктывкар».

На 01.01.2011 г. площадь сельскохозяйственных угодий во всех категориях земель составила 8,2 тыс. га (11,2 \% земельного фонда МО ГО «Сыктывкар»). На долю несельскохозяйственных угодий приходилось 65,1 тыс. га $(88,8$ \%). Анализ качественного состояния земель проводится один раз в пять лет в разрезе сельскохозяйственных угодий в составе земель сельскохозяйственного назначения. Площади по степени их проявления определяются по материалам почвенных обследований или проведённых специальных съёмок (эрозионные, солевые и др.).

Общая площадь земельного фонда МО ГО «Сыктывкар» по состоянию на 01.01.2011 г. составила 73,33 тыс. га и осталась без изменений. Распределение земельного фонда по категориям земель и угодьям приведено в таблице 2.

На 01.01.2011 г. площадь сельскохозяйственных угодий во всех категориях земель составила 8,2 тыс. га (11,2\% земельного фонда МО ГО «Сыктывкар»). На долю несельскохозяйственных угодий приходилось 65,1 тыс. га $(88,8 \%)$. 
Анализ качественного состояния земель проводится один раз в пять лет в разрезе сельскохозяйственных угодий в составе земель сельскохозяйственного назначения. Площади по степени их проявления определяются по материалам почвенных обследований или проведённых специальных съёмок (эрозионные, солевые и др.).

Таблица 2

Распределение земельного фонда по категориям земель и по угодьям, тыс. га

\begin{tabular}{|c|c|c|c|c|c|c|c|c|c|c|c|c|c|c|}
\hline \multirow{3}{*}{$\begin{array}{c}\text { Кате- } \\
\text { гория } \\
\text { земель }\end{array}$} & \multirow{3}{*}{$\begin{array}{c}\text { Общая } \\
\text { пло- } \\
\text { щадь }\end{array}$} & \multirow{3}{*}{$\begin{array}{c}\mathrm{C} / \mathrm{x} \\
\text { угодья }\end{array}$} & \multirow{2}{*}{\multicolumn{4}{|c|}{ в том числе }} & \multirow{3}{*}{$\begin{array}{c}\text { Под } \\
\text { водой }\end{array}$} & \multirow{3}{*}{$\begin{array}{c}\text { Бо- } \\
\text { ло- } \\
\text { та }\end{array}$} & \multirow{3}{*}{$\begin{array}{c}\text { Земли } \\
\text { заст- } \\
\text { ройки }\end{array}$} & \multirow{3}{*}{$\begin{array}{c}\text { Под } \\
\text { доро- } \\
\text { гами }\end{array}$} & \multirow{3}{*}{$\begin{array}{c}\text { Лесные } \\
\text { пло- } \\
\text { щади }\end{array}$} & \multirow{3}{*}{$\begin{array}{l}\text { Леса } \\
\text { вне } \\
\text { ЛФ }\end{array}$} & \multirow{3}{*}{$\begin{array}{l}\text { Наруш } \\
\text { земли }\end{array}$} & \multirow{3}{*}{$\begin{array}{l}\text { Про- } \\
\text { чие }\end{array}$} \\
\hline & & & & & & & & & & & & & & \\
\hline & & & ашня & $\begin{array}{l}\text { мн.лет. } \\
\text { насаж. }\end{array}$ & $\begin{array}{l}\text { сено- } \\
\text { косы }\end{array}$ & $\begin{array}{l}\text { паст- } \\
\text { бища }\end{array}$ & & & & & & & & \\
\hline 1 & 12,2 & 5 & 0,5 & 0,6 & 3,5 & 0,5 & 0,5 & 0,2 & 0,1 & 0,3 & 4,6 & 1,1 & 0,03 & 0,2 \\
\hline 2 & 16,8 & 3 & 1,3 & 0,3 & 0,8 & 0,5 & 0,6 & 0,02 & 5 & 0,5 & 5,4 & 0,4 & 0 , & 1,4 \\
\hline 3 & 4 & 0,02 & 0,01 & 0,01 & - & - & 1,3 & - & 0,1 & 0,2 & 1,9 & 0,01 & 0,01 & 0,5 \\
\hline 4 & - & - & - & - & - &  & - & - & - & - & - & - & - & - \\
\hline 5 & 40,2 & 0,2 & 0,02 & - & 0,2 & - & 0,1 & 0,9 & 0,03 & 0,2 & 38,2 & - & - & 0,6 \\
\hline 6 & - & - & - & - & - &  & - & - & - & - & - & - & - & - \\
\hline 7 & 0,2 & - & - & - & - & - & - & 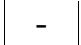 & - & - & 0,1 & 0,001 & - & 0,1 \\
\hline Итого & 73,3 & 8,2 & 1,8 & 1 & 4,5 & 1 & 2,5 & 1,1 & 5,7 & 1,4 & 50,2 & 1,5 & 0,05 & 2,7 \\
\hline
\end{tabular}

Если на отдельных участках проявляются несколько признаков, влияющих на плодородие, то площади определяются по каждому из признаков. Данные качественного состояния можно представить в виде таблицы 3.

Таблица 3

Качественное состояние земель, тыс. га

\begin{tabular}{|c|c|c|c|c|c|c|}
\hline Наименование угодий & $\begin{array}{c}\text { Общая } \\
\text { площадь }\end{array}$ & $\begin{array}{l}\text { в т.ч. обсле- } \\
\text { до-ванная }\end{array}$ & $\begin{array}{l}\text { Эрозионно- } \\
\text { опасные }\end{array}$ & $\begin{array}{c}\text { Дефля- } \\
\text { ционные }\end{array}$ & $\begin{array}{c}\text { Переувлаж- } \\
\text { ненные }\end{array}$ & $\begin{array}{l}\text { Заболо- } \\
\text { ченные }\end{array}$ \\
\hline $\begin{array}{l}\text { Сельскохозяйственные } \\
\text { угодья, в том числе }\end{array}$ & 5,045 & 3,249 & 0,056 & 0,167 & 0,166 & 0,311 \\
\hline пашни & 0,451 & 0,385 & 0,020 & 0,070 & - & 0,018 \\
\hline сенокосы & 3,475 & 2,464 & 0,020 & 0,052 & - & 0,256 \\
\hline пастбища & 0,484 & 0,390 & 0,016 & 0,045 & 0,166 & 0,037 \\
\hline
\end{tabular}

Анализ активности растительного покрова. Рассчитаны количественные критерии активности растительного покрова по муниципалитетам и их группам. Предложены стратегии землепользования на ближайшее будущее (табл. 4).

Данные земельного кадастра по Республике Коми на 01.01.2011, тыс. га

Таблица 4

\begin{tabular}{|c|c|c|c|c|c|c|c|c|c|c|c|}
\hline \multirow{3}{*}{$\begin{array}{c}\begin{array}{c}\text { Кате- } \\
\text { гория } \\
\text { земель }\end{array} \\
1\end{array}$} & \\
\hline & $\begin{array}{c}\text { Общая } \\
\text { площадь }\end{array}$ & $\begin{array}{c}\text { Всего } \\
\text { с/х } \\
\text { угодий }\end{array}$ & & $\begin{array}{r}\text { в то } \\
\text { Многол. } \\
\text { насажд. }\end{array}$ & $\begin{array}{l}\text { м числе: } \\
\text { сенокос }\end{array}$ & & $\left|\begin{array}{c}\text { Земли, } \\
\text { покрытые } \\
\text { лесом }\end{array}\right|$ & $\begin{array}{c}\text { Земли, не } \\
\text { покрытые } \\
\text { лесом }\end{array}$ & $\mid \begin{array}{c}\text { Леса вне } \\
\text { лесного } \\
\text { фонда }\end{array}$ & $\mid \begin{array}{c}\text { Бо- } \\
\text { лота }\end{array}$ & $\begin{array}{c}\text { Овра- } \\
\text { ги }\end{array}$ \\
\hline & 1862,9 & 299,2 & 75,9 & 4,8 & 168,6 & 49,9 & 445,9 & 30,5 & 100,9 & 82 & 0,2 \\
\hline 2 & 198,3 & 41,1 & 18,7 & 1,6 & 8,2 & 12,6 & 65,2 & 2,2 & 88 & 6,5 & 0,1 \\
\hline 3 & 270,3 & 0,3 & 01 & 0,0 & 0 & & 5 , & 3, & 5 , & 3,3 & 0,0 \\
\hline 4 & 2613,2 & 2,4 & 0 , & 0,0 & 2 , & & 158 & 19 & 0 , & 365,8 & 0,0 \\
\hline 5 & 35958,6 & 2,9 & 0 , & 0,0 & 50 & & 280 & 66 & & 3607,6 & 16,2 \\
\hline 6 & & & & 0,0 & & & & & & 0,0 & 0,0 \\
\hline 1 & 632,1 & 22,3 & 7,4 & 0,0 & 9, & $\mathrm{J}$, & & 4, & 20 & 7,9 & 0,0 \\
\hline Итого & 41677,4 & 418,2 & 102,5 & 6,4 & 239,6 & 69,7 & 30243,5 & 723,1 & 136,2 & 4073,1 & 16,5 \\
\hline
\end{tabular}

На территории Республики Коми соблюдается рациональное территориальное экологическое равновесие. Это видно из следующих количественных критериев:

1) абсолютная активность растительного покрова - 34768,5 тыс.га;

2) относительная активность (коэффициент активности) растительного покрова - 0,834 >> 0,618 (золотая пропорция);

3) лесистость (коэффициент лесистости) территории - 72,89\%; 
4) распаханность (коэффициент распаханности) территории - 0,25\%;

5) лесоаграрность (коэффициент лесоаграрности) территории - 296,387.

Это наглядно демонстрирует, что Республика Коми является многолесным и неаграрным субъектом федерации. Поэтому для дальнейшего развития территории следует обратить пристальное внимание на рекреационное освоение лесов.

Закономерности земельного кадастра Республики Коми. Получены устойчивые биотехнические закономерности распределения площади муниципалитетов.

По 20 муниципальным образованиям Республики Коми получена модель рангового распределения (рис. 1) в виде формулы

$$
S=3981,2801 \exp \left(-0,028554 r_{S}^{1,43472}\right),
$$

где $r_{s}$ - ранг убывания площади территории сельского района.

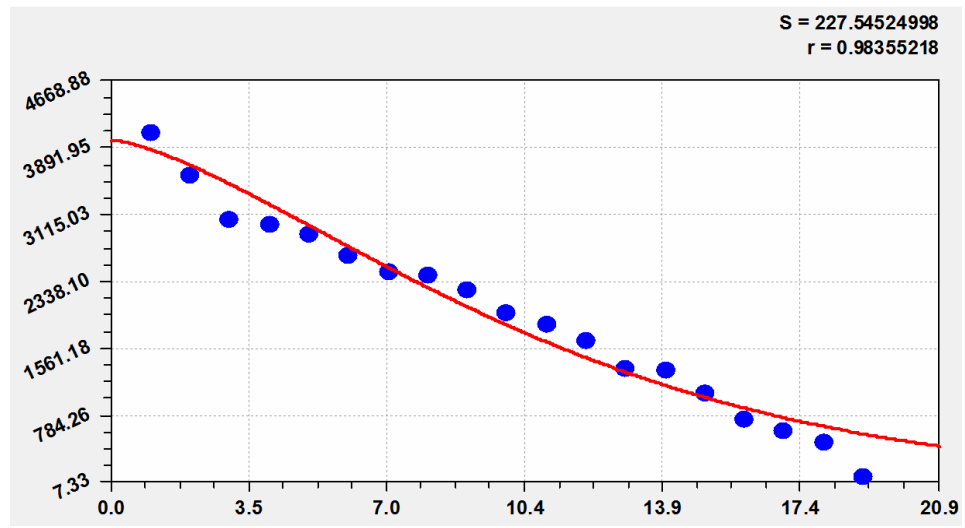

Рис. 1. Ранговое распределение площади муниципалитетов
Коэффициент корреляции формулы (1) составляет 0,9836 (в правом верхнем углу графика) и поэтому формула (1) очень точна.

Ранговое распределение муниципальных образований по площади сельхозугодий показано на рисунке 2.

Моделированием в программной среде CurveExpert была получена формула вида

$$
S_{C X У}=48,38951 \exp \left(-0,10263 r_{C X Y}^{1,02377}\right) .
$$

По всем 20 муниципалитетам Республики Коми отношение $\alpha=S_{C X У} / S$ (доля земель СХУ в процентах) изменяется (рис. 3) как предыдущие уравнения по закону экспоненциальной гибели

$$
\alpha=11,10564 \exp \left(-0,62004 r^{0,60390}\right) \text {. }
$$

Этот экспоненциальный закон популяционной динамики имеет очень высокий коэффициент корреляции 0,9907.

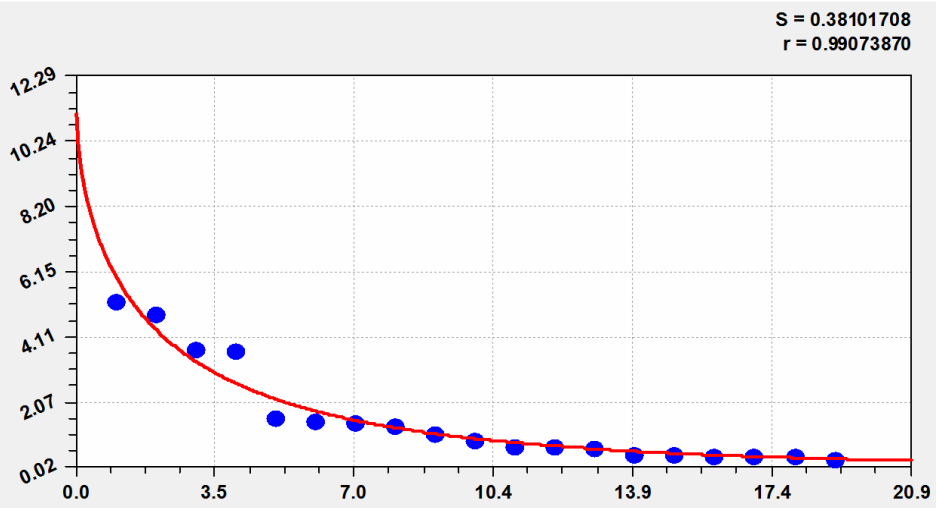

Рис. 3. Ранговое распределение муниципалитетов Коми по доле сельхозугодий в общей площади территории

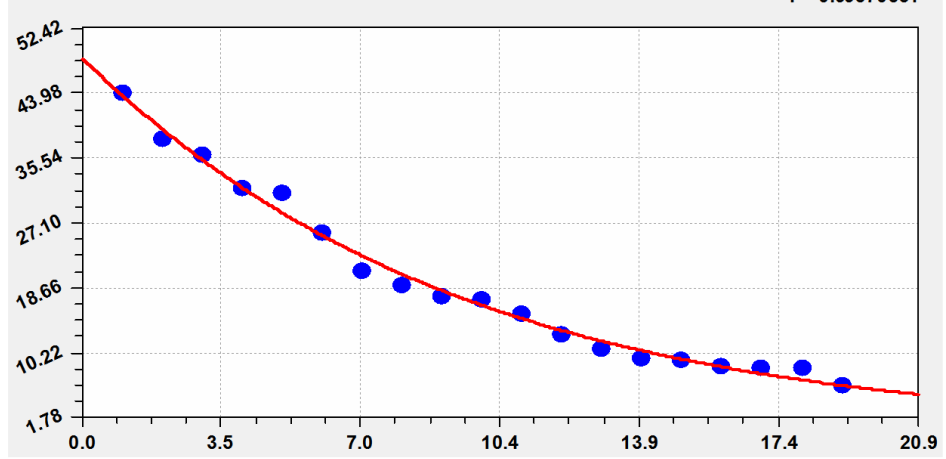

Рис. 2. Ранговое распределение муниципальных образований Коми по площади сельскохозяйственных угодий

Далее находим закономерность антропогенного влияния на территорию аграрным освоением.

Для этого нужно найти формулу вида $S_{C X y}=f(S)$, то есть определить влияние общей площади территории муниципалитета на площадь изъятых человеком земель в виде сельхозугодий.

По всем 20 точкам среднестатистическая закономерность показана на рисунке 4 и она имеет 
вид математического выражения

$$
\begin{gathered}
S_{C X Y}=6659078 S^{0,19226} \exp (-0,00015299 S)+ \\
+0,36624 \exp (0,00014291 S) \cos (\pi S / 363,26114+1,28811) .
\end{gathered}
$$

Формула (4) включает волновую составляющую, которая показывает антропогенное изменение территорий с нарастающей амплитудой по закону экспоненциального роста.

На основе полученных данных можно провести сравнительный анализ количественных критериев активности растительного покрова у трёх субъектов федерации (Республик Коми, Марий Эл и Чувашия) и представить результаты сравнения в виде таблицы 5.

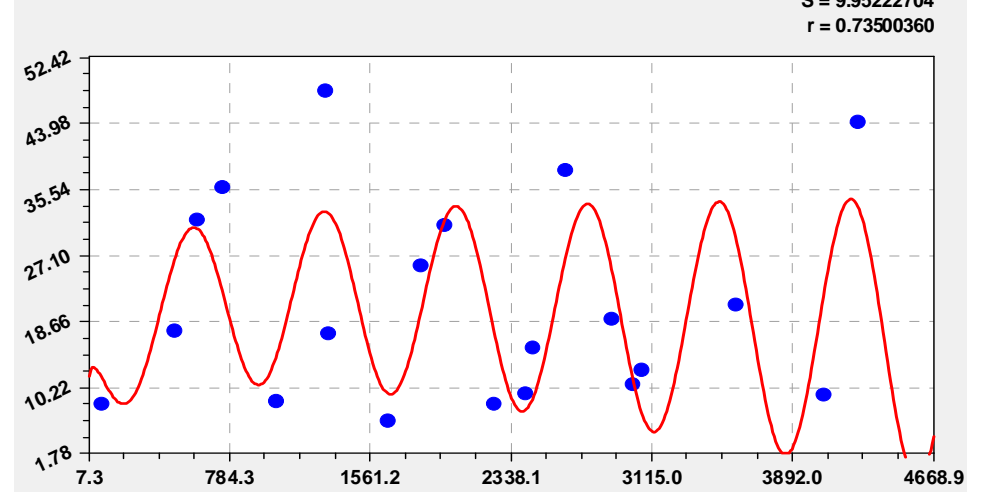

Рис. 4. График по модели (4) распределения площади сельхозугодий от общей площади муниципалитетов Коми

Таблица 5

Сравнение трёх субъектов федерации по показателям активности растительного покрова

\begin{tabular}{|l|c|c|c|}
\multicolumn{1}{|c|}{ Критерий активности растительного покрова } & $\begin{array}{c}\text { Республика } \\
\text { Коми }\end{array}$ & $\begin{array}{c}\text { Республика } \\
\text { Марий Эл [2] }\end{array}$ & $\begin{array}{c}\text { Республика } \\
\text { Чувашия [1] }\end{array}$ \\
\hline Абсолютная активность растительного покрова, тыс га & 34768,5 & 1539,7 & 808,373 \\
\hline Относительная активность растительного покрова & 0,834 & 0,659 & 0,440 \\
\hline Коэффициент лесистости территории & 0,7289 & 0,5672 & 0,3182 \\
\hline Коэффициент распаханности территории & 0,0025 & 0,2122 & 0,4450 \\
Коэффициент лесоаграрности территории & 296,387 & 2,672 & 0,715 \\
\hline
\end{tabular}

На основе проведённых теоретических и экспериментальных исследований были сформулированы основные научные выводы и рекомендации производству.

Выводы. Республика Коми обладает большими земельными, биологическими, водными, а также уникальными по разнообразию и качеству минерально-сырьевыми ресурсами (валовая ценность запасов полезных ископаемых республики достигает 11 трлн. долларов США или 8\% от прогнозного потенциала России), которые являются основой развития производительных сил.

Относительная активность растительного покрова Коми 0,834 выше золотой пропорции 0,618. Поэтому территориальное экологическое равновесие по республике соблюдается. Основной задачей является качественное обустройство территории и снижение риска экологических катастроф от возрастающего антропогенного влияния на природную среду. Следующей задачей, для повышения рекреационной привлекательности, является достижение к 2050 г. компонентного экологического равновесия.

\section{Библиографические ссылки}

1. Мазуркин П.М. Территориальный экологический баланс. - Йошкар-Ола: МарГТУ, 2011. - 72 c.

2. Мазуркин П.М. Экологический баланс территории: учеб. пос. с грифом УМО РАЕ. - Йошкар-Ола: Поволжский ГТУ, 2013. - 152 с.

3. Мазуркин П. М., Михайлова С.И. Территориальное экологическое равновесие = Territprial ecological balance: аналит. обзор; Учреждение Рос. акад. наук Гос. публич. науч.-техн. б-ка Сиб. отд-ния РАН, Марийс. гос. техн. ун-т. - Новосибирск: ГПНТБ СО РАН, 2010. - 430 с. (Сер. Экология. Вып. 94). 